\title{
Announcing the launch of the
}

\section{Review of \\ Symbolic Logic}

THE

REVIEW OF

SYMBOLIC LOGIC

ra
The Association of Symbolic Logic and Cambridge University Press are pleased to announce the founding of a new journal, The Review of Symbolic Logic. Joining the Journal of Symbolic Logic and the Bulletin of Symbolic Logic as the third official organ of the Association, RSL will publish research papers in:

- Philosophical and non-classical logics and their applications

- History and philosophy of logic

- Philosophy and methodology of mathematics

Volume 1 issues $1 \& 2$ to be published as a double issue in June 2008

For further information and to sign up for email alerts visit journals.cambridge.org/rsl

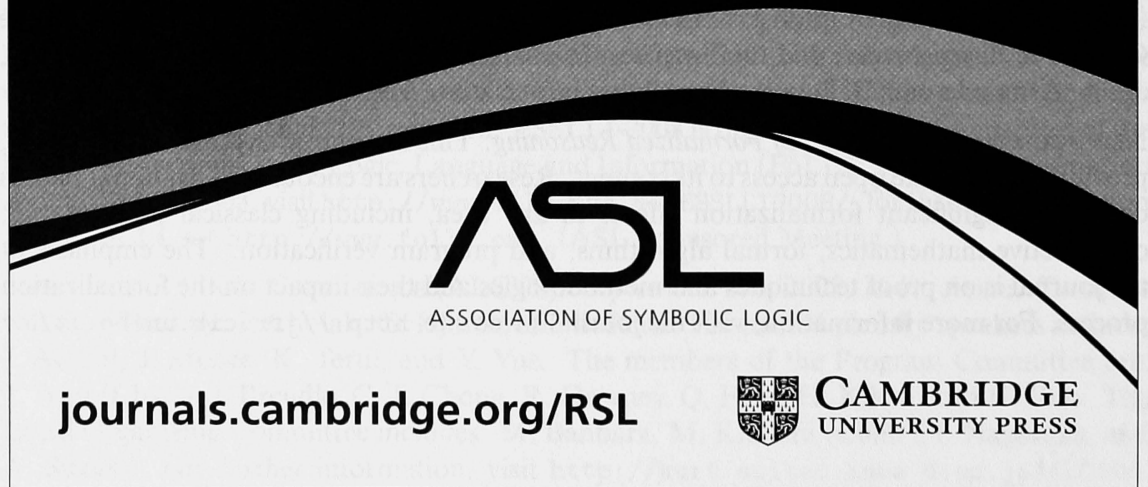


13TH Workshop on Logic, Language, Information and Computation (WoLLIC '2006), CSLI, Stanford, USA, July 18-21, $2006 \ldots \ldots \ldots \ldots \ldots \ldots \ldots \ldots \ldots \ldots \ldots . . \ldots \ldots$

Communications should be announcements of important new results and ideas in any aspect of logic; they may be short papers in their final form or preliminary announcements (extended abstracts, position papers) of longer, full papers that will be published elsewhere. In any case. they should include, in addition to a description of the new results or ideas, enough history, background, and explanation to make the significance of the work apparent to a wide audience. Communications will be quickly refereed and published within six months of the submission of final versions.

Articles and Communications being submitted for publication in the BULLETIN should be sent to one (and only one) of the following editors: John Baldwin, Dept. of Math., Stat., and Comp. Sci. (M/C 249), Univ. of Ill. at Chicago, 851 S. Morgan St, Chicago, IL 60607, USA (jbaldwin@uic . edu); or Rod Downey (Managing Editor), Department of Mathematics, Victoria University of Wellington, Box 600, Wellington, New Zealand (rod.downey@vuw ac. $\mathrm{nz}$ ); or Ilijas Farah, Department of Mathematics and Statistics, York University, 4700 Keele Street, Toronto, ON M3J 1P3, Canada (ifarah@mathstat.yorku.ca); or Phokion Kolaitis, Department of Computer Science, University of California Santa Cruz, Santa Cruz, CA 95064, USA (kolaitis@cse.ucsc.edu); or Penelope Maddy, Department of Logic and Philosophy of Science, University of California, Irvine, CA 92697, USA (pjmaddy@uci .edu); or Michael Rathjen, School of Mathematics, University of Leeds, Leeds LS2 9JT, UK (rathjen@maths. leeds . ac . uk); or Katrin Tent, Fakultät für Mathematik, Universität Bielefeld, Postfach 100131, D-33501 Bielefeld, Germany (ktent@math.uni-bielefeld.de). Submissions that are not readily categorized as either Articles or Communications should be sent to the managing editor.

Books for review in the BuLLETIN should be sent to ASL, Box 742, Vassar College, 124 Raymond Avenue, Poughkeepsie, NY 12604, USA. The Managing Editor for Reviews is Alasdair Urquhart, Department of Philosophy, University of Toronto, 215 Huron Street, Toronto, Ontario, Canada M5S1A1 (urquhart@cs . toronto . edu). The other editors of reviews are Steve Awodey (awodey@cmu.edu), John Baldwin (jbaldwin@math.uic.edu), Lev Beklemishev (lev@phil. uu.nl), Mirna Džamonja (M.Dzamonja@uea.ac.uk), David Evans (d.evans@uea.ac.uk), Erich Grädel (graedel@informatik.rwth-aachen. de), Denis Hirschfeldt (drh@math . uchicago. edu), Roger Maddux (maddux@iastate.edu), Luke Ong (Luke.Ong@comlab.ox.ac.uk) Grigori Mints (mints@csli.stanford.edu), Volker Peckhaus (peckhaus@hrz.upb.de), and Stawomir Solecki (ssolecki@math.uiuc.edu).

The editors prefer electronic submissions. The preferred formats for electronic submissions are PDF or postscript, but other formats, such as Word documents, will be accommodated as best as possible. The author should keep a complete copy of the submitted manuscript and the electronic files from which it was created. After the paper is accepted in its final form, an electronic copy will be appreciated and will advance the final publication date of the paper. It is preferred that papers be prepared in $\mathrm{L}_{\mathrm{E}} \mathrm{X}$ or other variant of $\mathrm{T}_{\mathrm{E}} \mathrm{X}$, especially for manuscripts that include extensive symbolic or mathematical notation. The ASL LTEX style files are available at http://www.aslonline.org, but their use is optional. Fifty offprints of each article are supplied at no charge; additional offprints may be purchased if desired.

Postscript files of articles published in the BULLETIN may be downloaded using a Web browser from http://www.math.ucla.edu/ asl/bsltoc.htm. All volumes of the BulLETIN also are available online in the JSTOR database.

Requests for information, applications for membership, orders for back volumes, business correspondence, and notices and announcements for publication in the BULLETIN should be sent to the Secretary-Treasurer of the Association, Charles Steinhorn, ASL, Box 742, Vassar College, 124 Raymond Avenue, Poughkeepsie, NY12604 USA. The electronic mail address of the Association's business office is asl@vassar. edu. The ASL Website is located at http://www . aslonline .org.

The paper used in this BuLLETIN is acid-free and falls within the guidelines established to ensure permanence and durability. 


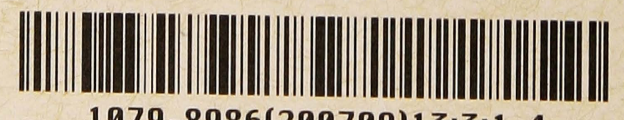

1079-8986(200709)13:3;1-4 